فاعلية برنامج تعليمي مدعم بالهاتف النقال على مستوى أداء بعض المهارات الأساسية في كرة القدم بلدرس التربية الرياضية

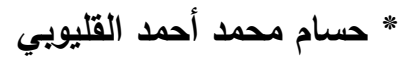

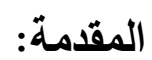

إن التعليم لم يكن في أي عصر من العصور أو حقبة من الزمن، بمنأى عن الظروف المجتمعية المحيطة به فهو يؤثر ويتأثر بكل ما يدور في المجتمع من أحداث وتغيرات تفرض نفسها على المجتمعات المعاصرة. يشير "أحمد سالم" († . . بم) إلى أن فكرة الهاتف النقال جاءت من فكرة عمل الراديو، فقد وجد الباحثون

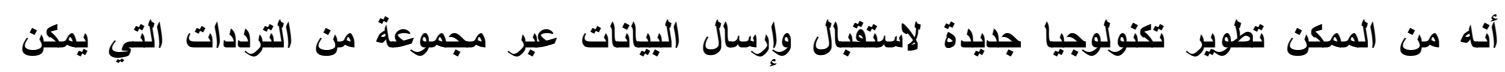

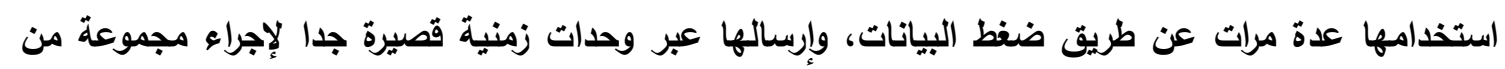

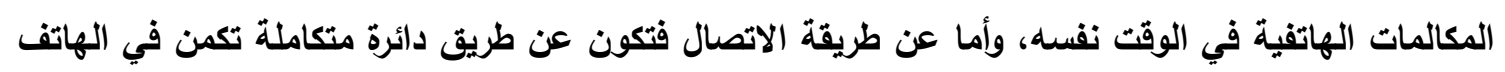

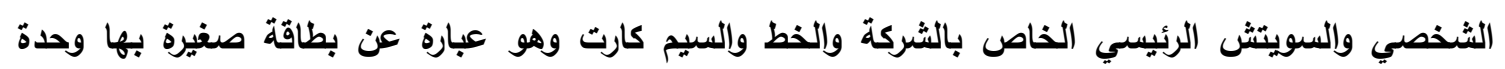

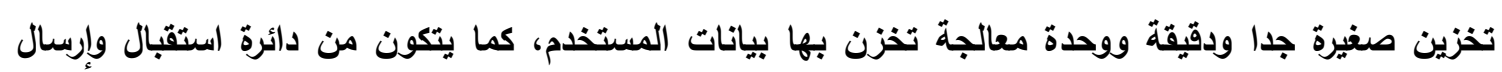

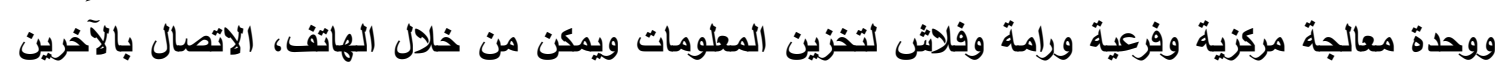

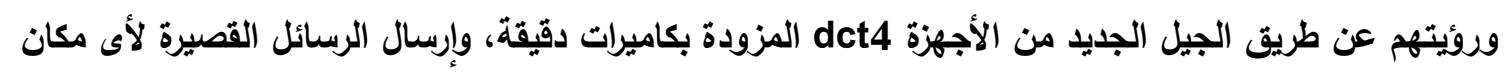

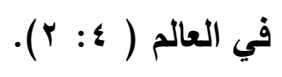

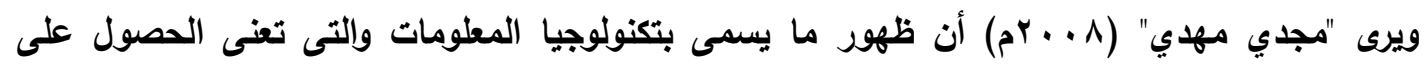

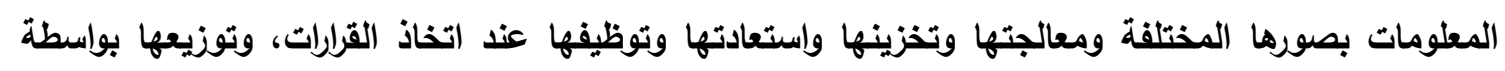

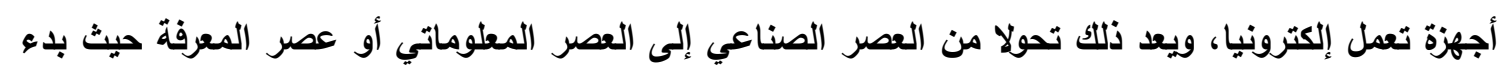

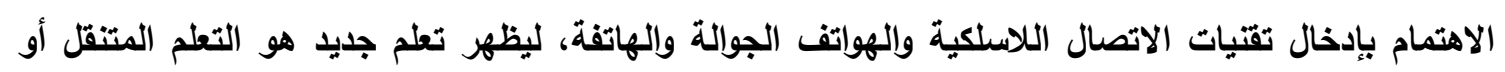

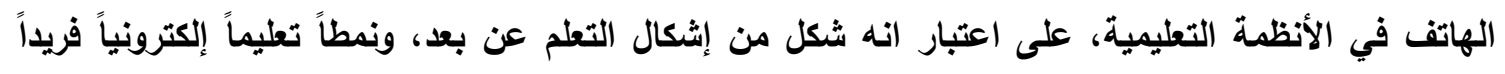

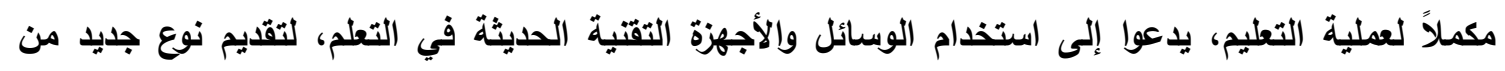

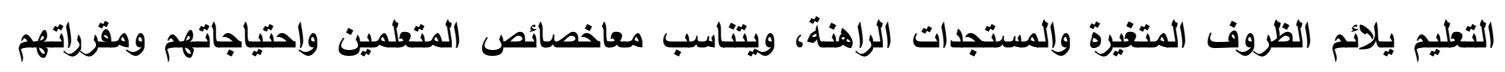

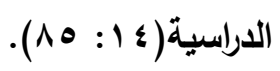

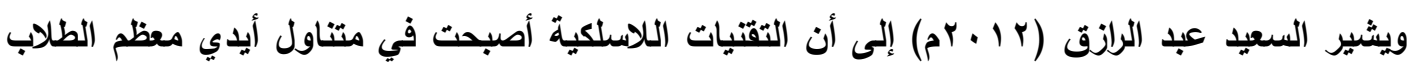

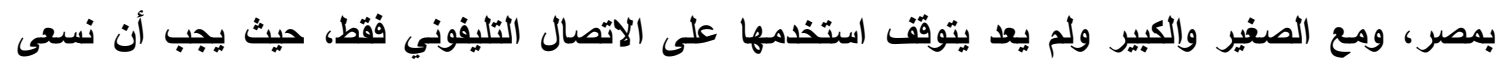

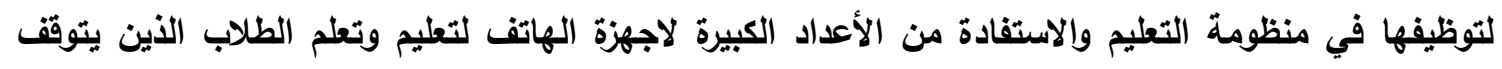

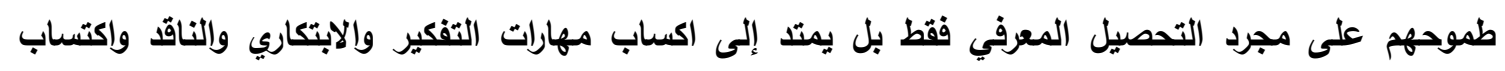

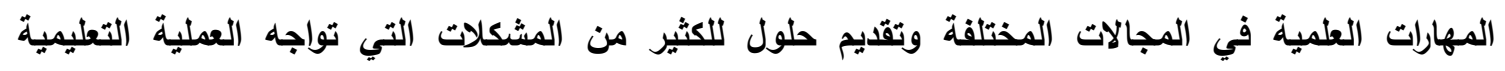

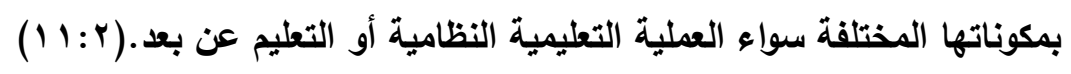




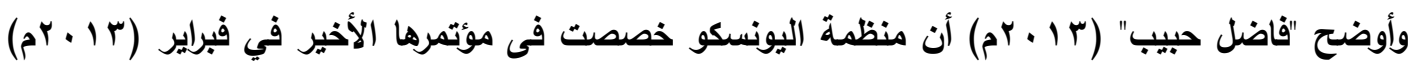

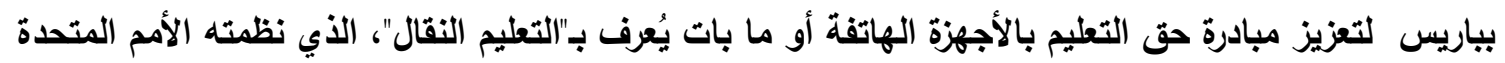

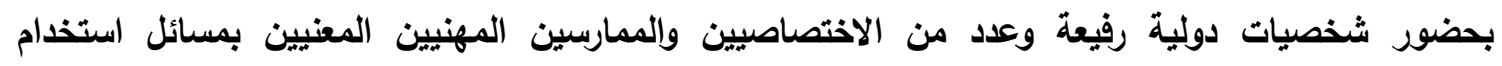
تكنولوجيا المعلومات والاتصالات في مجال التعليم ومندوبين من المنظمات غير الحكومية والثركات المعنية لوضع الأساليب المبتكرة للتعلّم باستخدام تكنولوجيات الأجهزة الهاتفة ومن خلالها، وإمكانية إسهام هذهاته التكنولوجيات في تحقيق أهداف التعليم للجميع وفي تحسين جودة التعليم (س ال ه ه).

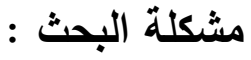

يعد نشاط كرة القدم من الأنشطة الأساسية في منهاج التربية الرياضية للمرحلة الاعدادية والذي من

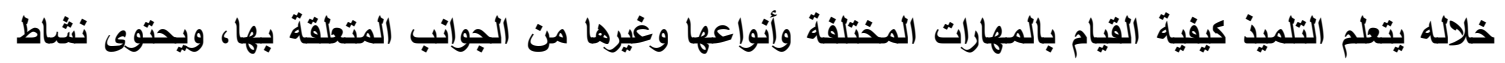
كرة القدم على تطبيقات متعددة وتحتاج إلى شرح وتوضيح إضافي عنها خارج وقت النشاط الاعتيادي وذلك لقلة الوقت المخصص لها مما يتطلب توفير وقت إضافي للتلاميذ خارج وقت النشاط لغرض تزويدهم بمعلومات إضافية عن النشاط الذى قاموا بدراسته من أجل تحسين وزيادة استيعابهم لها بصورة جيدة من خلال استخدام الوسائل التعليمية المساعدة والمتاحة لتحقيق هذا الغرض وخاصة التقتيات التريوية الحديثة ومنها تقنيات التعليم الإكتروني المختلفة بمختلف جوانبه.

والبحث الحالي يسعى إلى إلقاء الضوء على بعض الجوانب المتعلقة باستخذام الهاتف النقال في التعليم

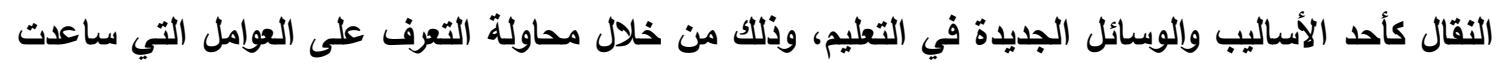

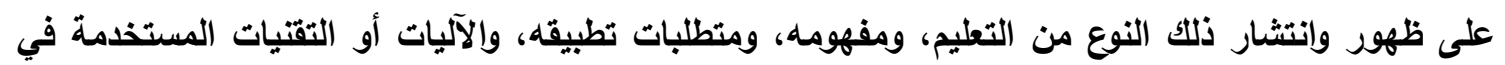
ذلك، والفوائد التريوية من استخدامه في التعليم، والتحديات أو الصعويات التي تواجه استخدامه في ذلك.

ومن هنا أى للباحث أن يقوم بتجريب أحد الوسائل والتقنيات التي قد تسهم في الارتقاء بالمستوى

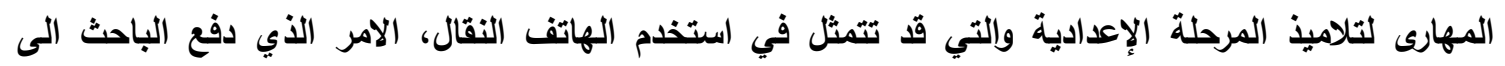

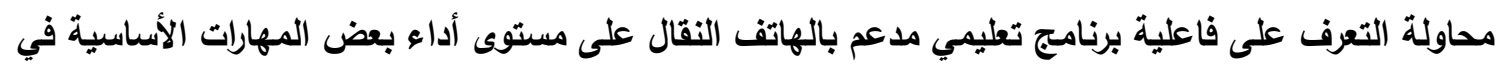
كرة القدم بدرس التربية الرياضية. أهمية البحث: - - أنه يسهم في القاء الضوء على كيفية الاستفادة مما نحمله فى أيدينا من هواتف فى إحداث نقلة نوعية في

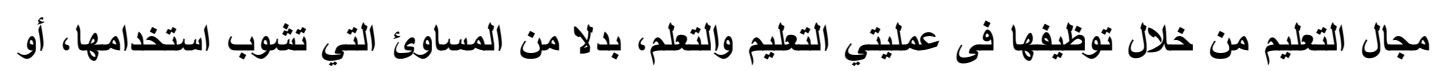
اقتصار استخدامها على إرسال واستقبال المكالمات الهاتفية.

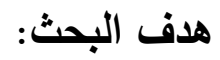
يهدف هذا البحث إلى محاولة التعرف على فاعلية برنامج تعليمى مدعم بالهاتف النقال على مستوى أداء بعض المهارات الأساسية في كرة القدم بدرس التربية الرياضية. 
ا. توجد فروق دالة إحصائيا بين القياسين القبلي والبعدي للمجموعة الضابطة (الشرح والعرض) في مستوى

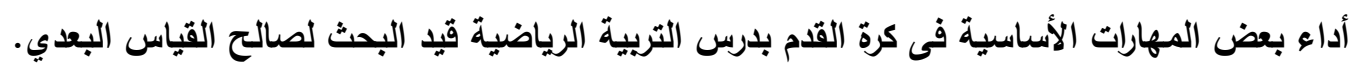

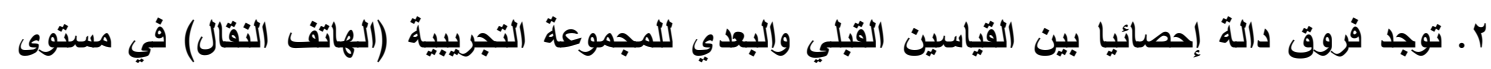

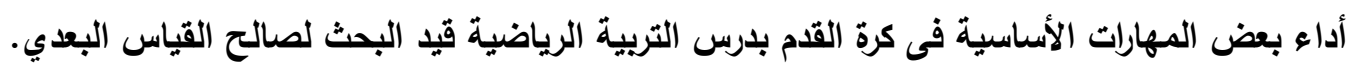
r. توجد فروق دالة إحصائيا بين القياسيين البعديين للمجموعة الضابطة (الثرح والعرض) والمجموعة لإنيه التجريبية (الهاتف النقال) في مستوى أداء بعض المهارات الأساسية فى كرة القدم قيد البحث لصائ لصالح

المجموعة التجريبية.

مصطلحات البحث:

التعليم بالهاتف:

يعرفه كل من "جمال الدهثان" و"مجدي يونس" ( • ( • rم) التعليم بالهاتف بأنه" ذلك النوع من التعليم والتعلم

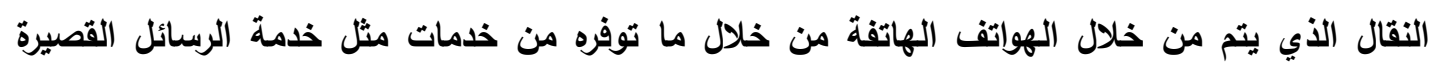

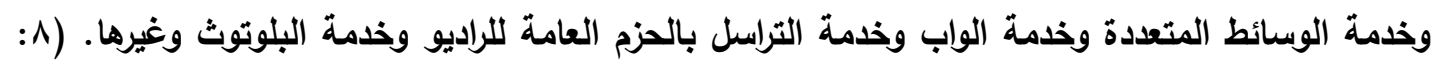

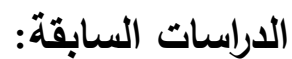

1. دراسة "أحمد صيام" (10 • rم) واستهدفت تصميم برمجية تعليمية إلكترونية تسمى بالكتيب الإلكتروني وذلك للتعرف على فاعلية برنامج تعليمي باستخدام الكتيب الإكتروني في جوانب التعلم لبعض المهابه المهارات الأساسية لكرة القدم لتلاميذ المعاهد الإعدادية الأزهرية، واستخدام الباحث المنهج التجريبي وتكونت التهي العينة

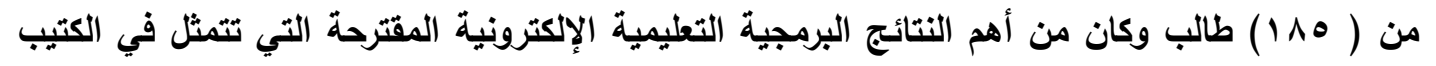
الإكتروني ساهمت بطريقة إيجابية في تعلم بعض المهارات الأساسية لكرة القدم قيد البحث لتلاميذ المجموعة التجريبية والطريقة المعتادة ساهمت بطريقة إيجابية في تعلم بعض المهابة لهارات الأساسية لكرة

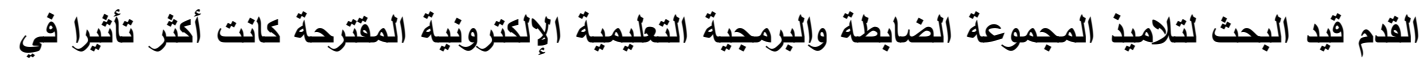

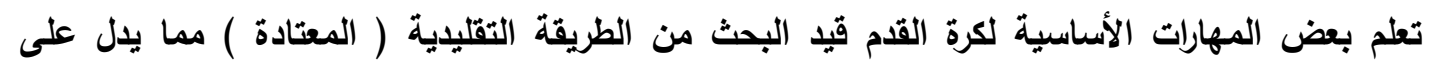

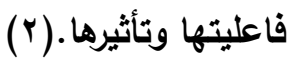

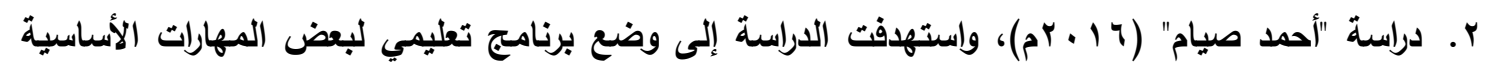

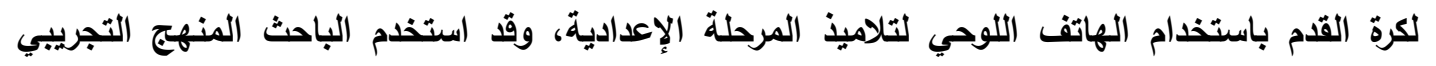

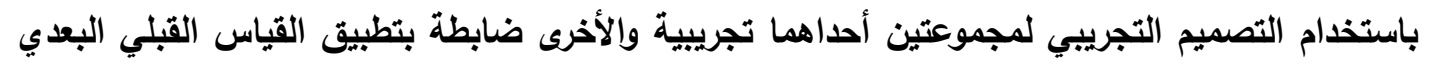
لكل مجموعة وذلك لملائمته لطبيعة يمثل مجتمع البحث تلاميذ الصف الثالث الإعدادي بالمعاهد الأزهرية

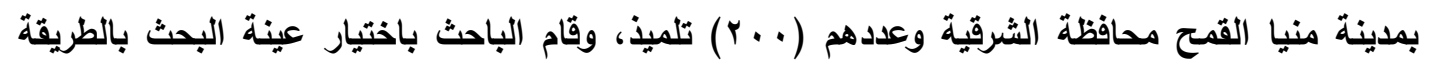

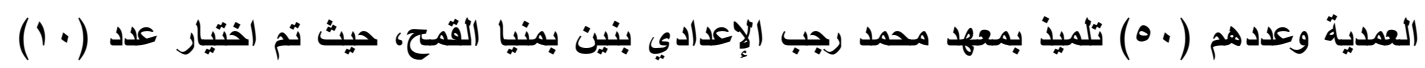

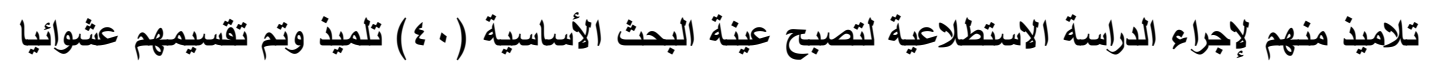

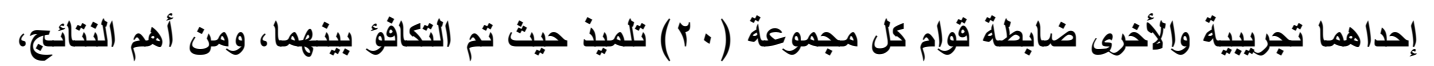


استخدام الهاتف اللوحي في تعلم بعض المهارات الأساسية لكرة القدم لتلاميذ المرحلة الإعدادية لما أثبتته نتائج هذه الدراسة، وضرورة توافر أجهزة الهاتف اللوحي في المدارس واستخدامها في عملية تعلم المهارات

الحركية بالأنثطة الرياضية بصفة عامة ورياضة كرة القدم بصفة خاصة بدرس التربية الرياضية. (r)

r. دراسة "محمد عبد الحليم" (V V · rم)، واستهدفت الدراسة إلى قياس فاعلية النموذج المقترح لتطوير بنية نظام إدارة محتوى تعليمي قائم على التعليم الجوال في تتمية الجانب المعرفي لمادة تطبيقات الحاسب الآلي في التعليم لاى لطلاب كلية التربية النوعية بيورسعيد جامعة بورسعيد، واستخدم الباحث المنهج التجريبي

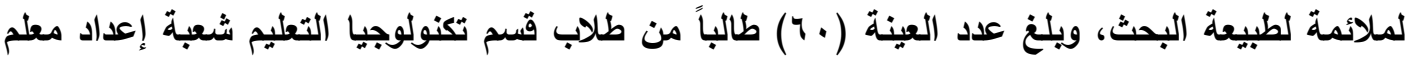
حاسب الي، وكانت أهم النتائج لهذه الاراسة هى أن المحتوى الإلكتروني القائم على الأجهزة الجوالة في أي وقت ومن أي مكان، وما يوفره من إمكانية تقديم تغذية راجعة للطلاب، من خلال تصحيح الأنثطة والمهام المرسلة من قبلهم، وتوضيح نقاط الضعف لايهم للعمل على تصحيحها، كما تم وضع فيديوهات

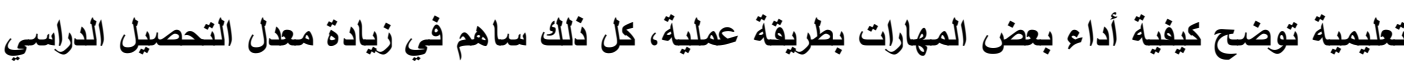

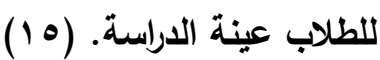
ع. دراسة "كيم سوك " Hea-Suk، Kim (ع ا +rم)، واستهدفت معرفة أثر استخدام الأجهزة النقالة في

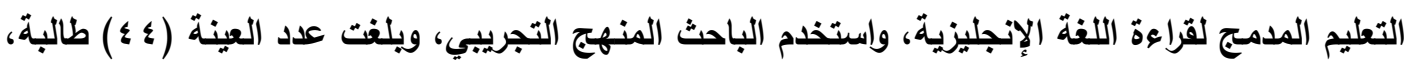
وكانت أهم النتائج أن استخدام الهاتف الهواتف يعطي إمكانية جديدة حيث يمكن للطلاب أن تشارك بصورة

فردية في أنشطة القراعة في أي مكان وفي أي وقت من خلال التفاعل مع الأقران. (9 1 ( )

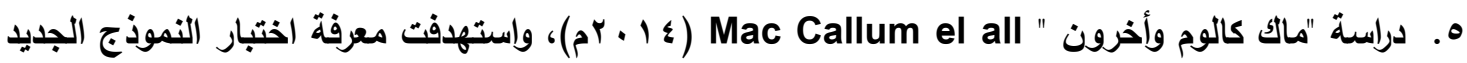
مع ثلاثة متغيرات جليدة- رقمية مضاعة والقلق تكنولوجيا المعلومات والاتصالات ، وتكنولوجيا المعلومات

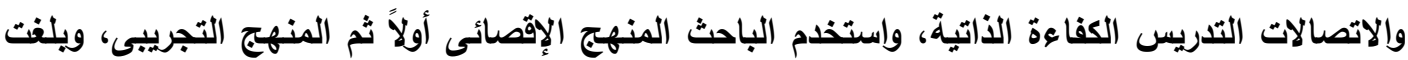

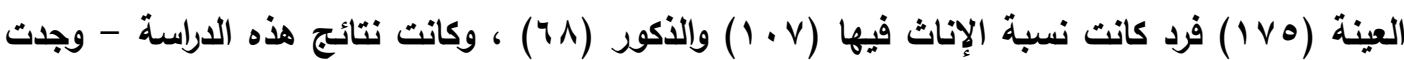
هذه الدراسة أن محو الأمية الرقمية، والقلق من تكنولوجيا المعلومات والاتصالات، وتدريس الكفاءة

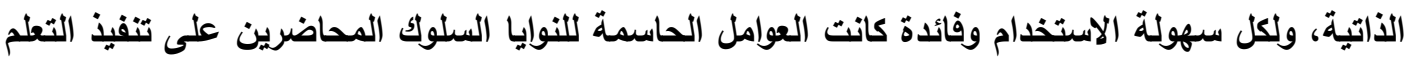
النقال، - وأكد هذا البحث الدور المتصور لسهولة الاستخدام والفائدة من التعلم النقال، واعتماد المحاضرين على نموذج التعلم النقال، -.يشير البحث إلى دور سلبي من القلق تكنولوجيا المعلومات

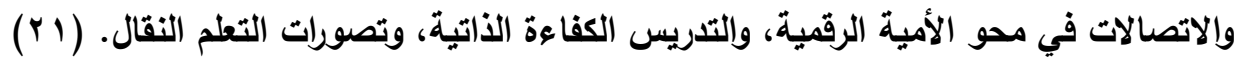

$$
\text { التعليق على الاراسات السابقة: }
$$

من خلال العرض السابق للاراسات السابقة (العربية والاجنبية) يتضح ما يلي تعدد هذه الدراسات التي تعتبر المرجع التطبيقي لتوجيه الباحث من حيث اختيار المنهج والأدوات وكذلك الإجراءات المتبعة، وإثتملت الدراسات علي استخدام الكمبيوتر اللوحي وتكنولوجيا التعليم وأثره الإيجابي في العملية التعليمية ورفع مستوي التحصيل المعرفي وتحسين الأداء المهارى، ويستخلص الباحث من عرض الدراسات السابقة أهمية الأسلوب مئي العلمي لتحقيق الأهداف عن طريق خطوات محدة للوصول إلي النتائج وتفسيرها وعرضها من خلال منهاجية معينة تحقق هذه الأهداف. 
من حيث تصنيف الدراسات:بلغ عدد الدراسات المرتبطة (ه) دراسة بواقع (ז) دراسة عربية، (ץ) دراسات أجنبية.

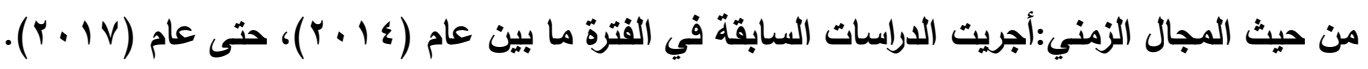
من حيث عدد العينات:تنوعت العينات ما بين الفئات التالية:تراوحت العينات ما بين (ع ؛)، (. ب) طالب وتلميذ.

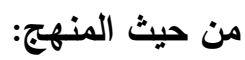

اتفقت أغلب الدراسات السابقة على استخدام المنهج التجريبي باعتباره أنسب المناهج لمثل هذه

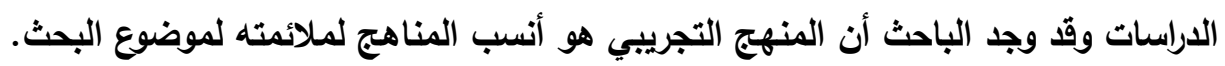

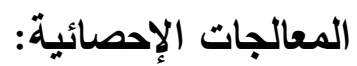

تباينت الدراسات السابقة في استخام المعالجات الإحصائية وذلك طبقاً لمتغيرات وطبيعة أهداف كل

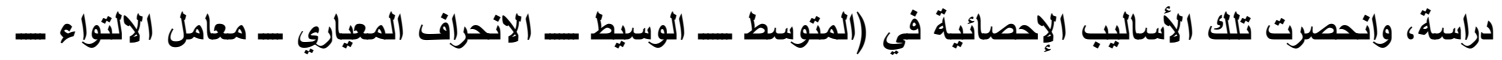

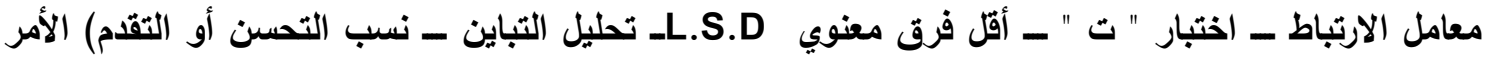
الذي أفاد الباحث في اختيار الأسلوب الإحصائي المناسب لطبيعة البحث. من حيث أهم النتائج : جاءت نتائج معظم الدراسات كالتالي:

() استخدام الهاتف اللوحي في تطم بعض المهارات الأساسية لكرة القدم لتلاميذ المرحلة الإعادية، وضرورة توافر أجهزة الهاتف اللوحي في الدارس واستخدامها في عملية تعلم المهارات الحركية

بالأنثطة الرياضية بصفة عامة ورياضة كرة القدم بصفة خاصة بدرس التربية الرياضية.

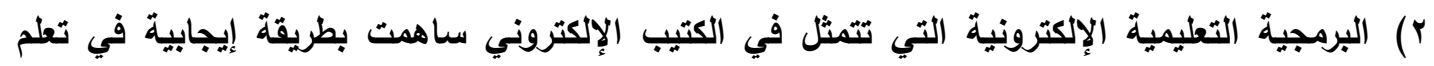
بعض المهارات الأساسية لكرة القدم.

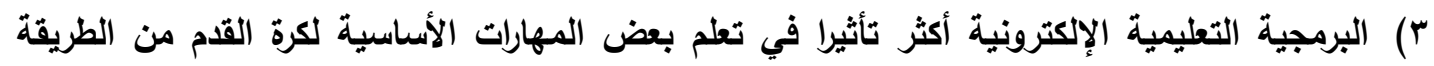
التقليدية (المتثادة) مما يال على فاعليتها وتأثيرها.

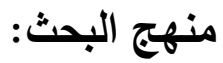

استخدم الباحث المنهج التجريبي، وذلك بالتصميم التجريبي لمجموعتين إحداهما ضابطة، والأخرى تجريبية ذو القياسين القبلي والبعدى وذلك لمناسبة لطبيعة البحث. مجتمع وعينة البحث:

يتمثل مجتمع البحث الحالي من تلاميذ المرحلة الإعدادية بمدرسة علي بن أبي طالب الإعدادية بمحافظة

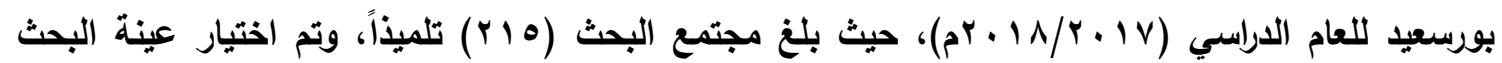
بالطريقة العددية العشوائية من تلاميذ المرحلة الإعدادية بمدرسة علي بن العيد أبي طالب الإعدادية بمحافظة

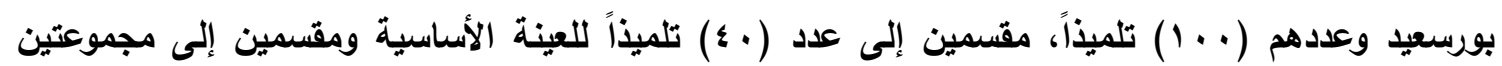




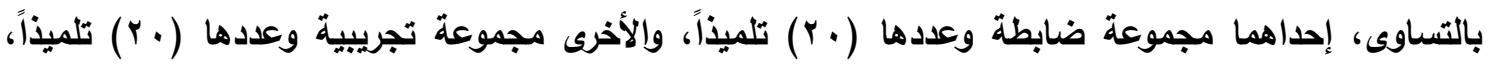
ومجموعة للاراسات الاستطلاعية وعددها ( • ؟) تلميذاً، ومن نفس المجتمع وخارج العينة الأساسية، وذلك ولإجراء المعاملات العلمية للاختبارات المهارية وتجريب البرنامج التعليمى المصمم عبر الهاتف النقال لمناسبة لعينة البحث.

$$
\text { تجانس وتكافؤ عينة البحث في المتغيرات والاختبارات قيد البحث: }
$$

تم اجراء التجانس والتكافؤ على عينة البحث الأساسية للمجموعتين الضابطة والتجريبية والبالغ عددهم

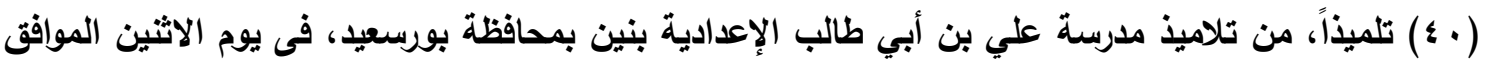

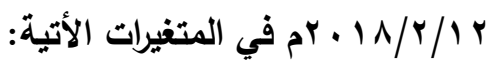

$$
\text { ( ) معدلات النمو: (السن - الطول - الوزن). }
$$

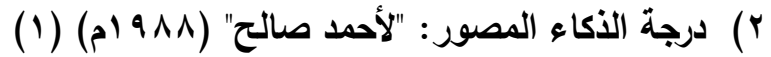

r) اختبار مستوى الاداء المهارى: استخدم الباحث اختبارات مستوى الأداء المهارى للمهارات الأساسية

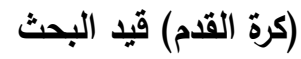

\begin{tabular}{|c|c|c|c|c|c|c|c|c|c|c|}
\hline \multicolumn{4}{|c|}{ المجموعة التجريبية } & \multicolumn{4}{|c|}{ المجموعة الضابطة } & \multirow{2}{*}{ وحدة } & \multirow{2}{*}{ /الإحصاء / } & \multirow{2}{*}{ p } \\
\hline الالتواء & الوسبط & $\varepsilon \pm$ & س-- & الالتواء & الوسيط & $\varepsilon \pm$ & س- & & & \\
\hline r & $1 \vee 0 \ldots$ & Y.. o & IVo.Yo & $\begin{array}{c}- \\
. Y \sigma^{-}\end{array}$ & $180 \ldots$ & $1 . V \Lambda$ & $1 \vee 0 \ldots$ & سنه//شهر & السن & 1 \\
\hline. .11 & $1 \leq \mu \ldots$ & 0.99 & $1 \leq \mu . \varepsilon$. &. .94 & $1 \leq \varepsilon \ldots$ & $7 . \leqslant Y$ & $1 \leq \varepsilon .1$. & سم & الطول & r \\
\hline..$\leqslant 0$ & $\leq 0 .$. & $\varepsilon . \wedge \varepsilon$ & $\varepsilon 7.10$ & $\ldots r$ & $\varepsilon V . \ldots$ & $\varepsilon . \varepsilon$. & $\varepsilon V . \ldots$ & كجم & الوزن & $r$ \\
\hline .. & $\$ 1.0$. & r.va & $\leqslant 1.70$ & $.0 \leq$ & $\varepsilon r .0$. & r.07 & \& Y. ૫० & درجة & الأكاء & $\varepsilon$ \\
\hline
\end{tabular}

تجانس عينة البحث فى معدلات النمو (السن والطول والوزن) ودرجة الذكاء:

$$
\text { (1) (1) (1) }
$$

معامل الالتواء للمجموعتين الضابطة والتجريبية فيالسن والطول والوزن ودرجة الذكاعن ا=ن r= ب r

$$
\text { الخطأ المعياري لمعامل الالتواء = (101. ) }
$$

يتضح من جدول (1) أن قيم معامل الالتواء للمجموعة الضابطة في السن والطول والوزن والذكاء تراوحت

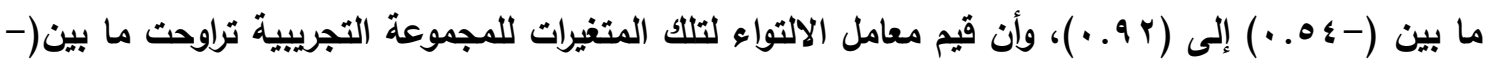




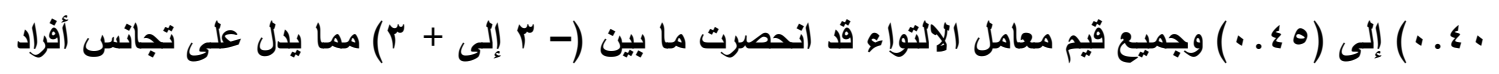
المجموعتين الضابطة والتجريبية في تلك المتغيرات. تجانس عينة البحث فى مستوى أداء بعض المهارات الأساسية قيد البحث جدول (r) معامل الالتواء للمجموعتين الضابطة والتجريبية فى مستوى أداء

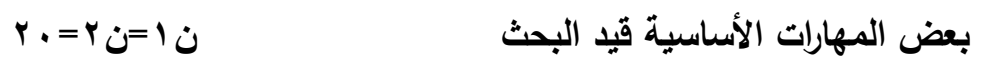

\begin{tabular}{|c|c|c|c|c|c|c|c|c|c|c|}
\hline \multicolumn{4}{|c|}{ المجموعة التجريبية } & \multicolumn{4}{|c|}{ المجموعة الضابطة } & \multirow{2}{*}{ وحدة } & \multirow{2}{*}{ الإحصاء } & \\
\hline الالتواء & الوسبط & $\varepsilon \pm$ & س- & الالتواء & الوسبط & $\varepsilon \pm$ & س- & & & \\
\hline$\cdots 4$ & $1 \ldots$ & $\therefore \wedge 9$ & 1.r. & $.1 r-$ & $1 \ldots$ & .00 & $\because v \theta$ & عدد & تصويب الكرة بالرأس & 1 \\
\hline $1.0 r$ & $\cdots$ &. .09 & or. &. $.7 \wedge$ & $\cdots$ & $\therefore \leqslant 9$ & . r. & ث & متراً على المرمى من (ro) & $r$ \\
\hline . . $\leqslant 1$ & E.Yo & $. \wedge \leqslant$ & $\varepsilon .1 T$ & $\cdot \varepsilon \cdot-$ & $\varepsilon \ldots 0$ & 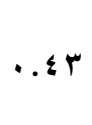 & $r .91$ & عدد & مسافة & $r$ \\
\hline
\end{tabular}

$$
\text { الخطأ المعياري لمعامل الالتواء =( (1. + ) }
$$

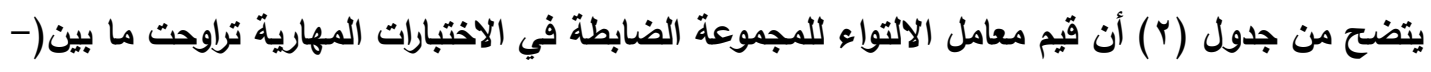

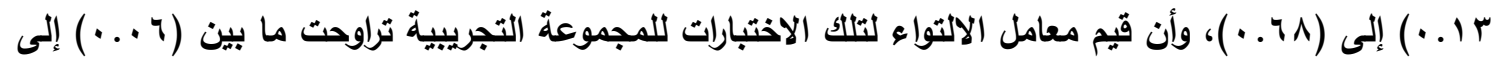

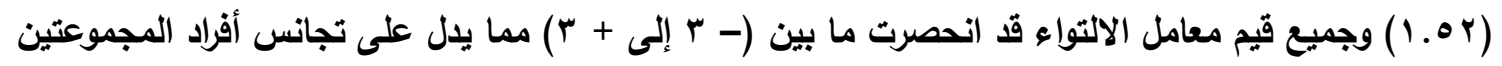
الضابطة والتجريبية في تلك الاختبارات. تكافوُ عينة البحث فى معدلات النمو (السن والطول والوزن) ودرجة الأكاء: 


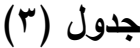

دلالة الفروق بين المجموعتين الضابطة والتجريبية في السن والطول والوزن ودرجة الذكاعن ا = ن ب=. r

\begin{tabular}{|c|c|c|c|c|c|c|c|c|}
\hline \multirow{2}{*}{ مستوى الالالة } & \multirow{2}{*}{ قيمة (ت) } & \multirow{2}{*}{ الفرق بين } & \multicolumn{2}{|c|}{ المجموعة التجريبية } & \multicolumn{2}{|c|}{ المجموعة الضابطة } & \multirow{2}{*}{ /المتغيرات / الاحصاء } & \multirow{2}{*}{ م } \\
\hline & & & $\varepsilon^{ \pm}$ & س- - س & $\varepsilon \pm$ & س- & & \\
\hline. .71 & 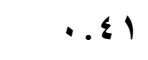 & .ro- & r... & IVO.Yo & $1 . \vee \wedge$ & ivo... & السن السن & 1 \\
\hline.$v$. &.$r \Lambda$ &.$v$. & $0 . .9$ & $1 \leq r . \varepsilon$. & T. $\{Y$ & $1 \leq \varepsilon .1$. & الطول & r \\
\hline .07 &. .01 &.$\wedge 0$ & $\varepsilon . \wedge \varepsilon$ & $\leq 7.10$ & ะ. . & $\varepsilon V \ldots$ & الوزن & $r$ \\
\hline . &. .14 & $1 \ldots$ & r.vq & $\$ 1.70$ & $r .07$ & $\leqslant$ Y.. & الأكاء & $\varepsilon$ \\
\hline
\end{tabular}

يتضح من جدول (r) أن قيمة (ت) الجدولية باختبار(T-TEST) قـ بلغت بين المجموعتين الضابطة

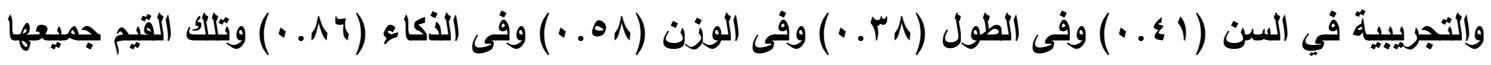

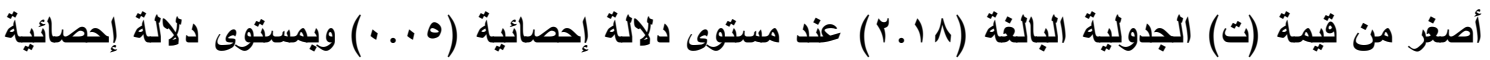

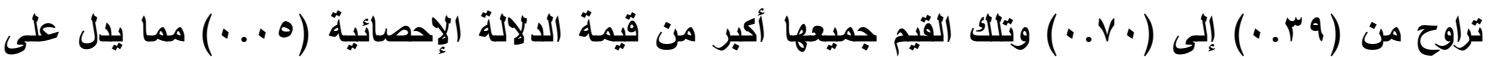
تكافؤ المجموعتين الضابطة والتجريبية في تلك المتغيرات. تكافؤ عينة البحث فى مستوى أداء بعض المهارات الأساسية قيد البحث:

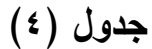

دلالـــة الفروق بين المجموعتين الضابطة والتجريبيـة فى مستوى أداء بعض المهارات الأساسية قيد البحث $r_{\cdot}=r \dot{U}=1 \dot{0}$

\begin{tabular}{|c|c|c|c|c|c|c|c|c|}
\hline \multirow{2}{*}{ مستوى الدلالة } & \multirow{2}{*}{ قيمة (ت) } & \multirow{2}{*}{ الفرق بين } & \multicolumn{2}{|c|}{ المجموعة التجريبية } & \multicolumn{2}{|c|}{ المجموعة الضابطة } & \multirow[t]{2}{*}{ الإحصاء } & \\
\hline & & & $\varepsilon \pm$ & 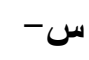 & $\varepsilon \pm$ & 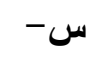 & & \\
\hline$\ldots 7$ & $1.9 r$ &.$\leqslant 0-$ &..$\wedge 9$ & I.r. & .00 & $\because v_{0}$ & تصويب الكرة بالرأس نحو المرمى & 1 \\
\hline $1 \ldots$ & $\cdots$ & $\cdots$ &. .09 & .ro & $\cdots \leqslant 9$ & $\cdot \mu_{0}$ & ركل الكرة من هب متراً على المرمى & r \\
\hline$\cdots$ &. $.4 \wedge$ & $.10-$ &.$\wedge \varepsilon$ & $\{.1 \%$ &..$\leqslant r$ & $r .91$ & رية التماس لأبعد مسافة & $r$ \\
\hline
\end{tabular}

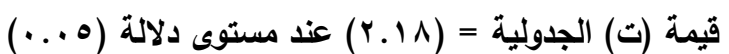


يتضح من جدول (؛ ) أن قيمة (ت) الجدولية قد بلغت بين المجموعتين الضابطة والتجريبية في تصويب

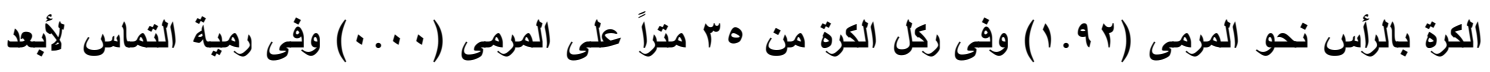

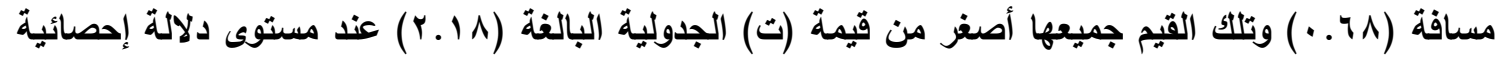

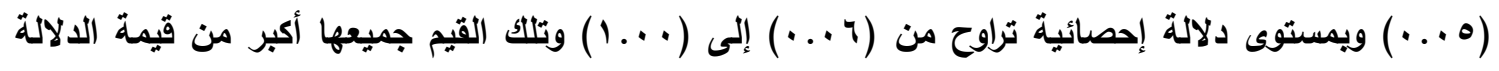

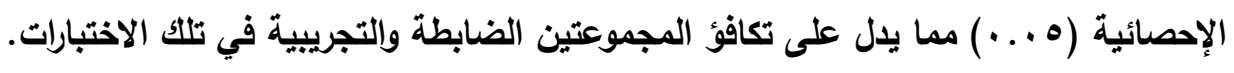

وسائل وأدوات جمع البيانات : استخدم الباحث الأدوات والأجززة الأتية:

$$
\begin{aligned}
& \text { 1- القياسات الخاصة بمعدلات النمو: } \\
& \text { أ- السن (الرجوع إلى تاريخ الميلاد من السجلات لاقرب شهر) }
\end{aligned}
$$

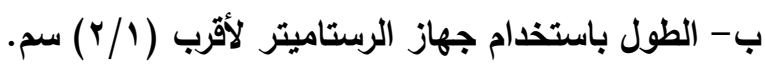

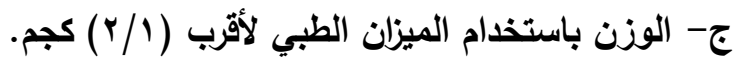

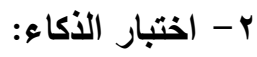

قام الباحث باختيار اختبار الأكاء المصور "لأحمد صالح" (911 ام) (1) وقد اختار الباحث هذاء

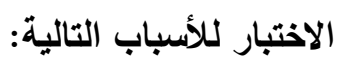

أ- يعتبر من الاختبارات الخاصة بتقدير القدرة العقلية لاى الأفراد من سن الثامنة إلى السابعة عشر. ب- يُعتبر من الاختبارات غير اللفظية ولا يعتمد على إجادة اللغة العربية. ج- يمكن تطبيقه على عدد كبير في نفس الوقت.

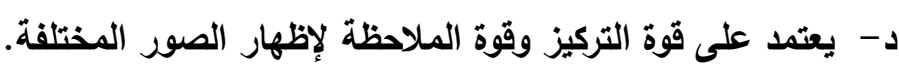

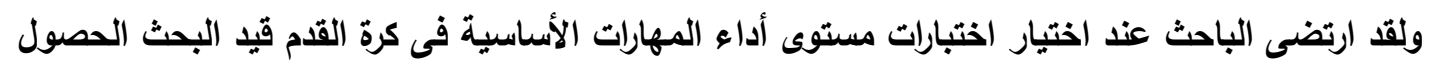

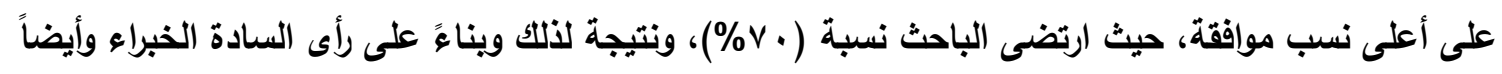
تبعا لاختبارات تقييم الأداء فى كرة القدم فى دليل معلم التربية الرياضية للصف الثاني الإعدادي. تم اختيار الاختبارات التالية وذلك تبعاً للمنهج الادراسي المقرر على تلاميذ المرحلة الإعدادية:

$$
\begin{aligned}
& \text { 1- تصويب الكرة بالرأس نحو المرمى. }
\end{aligned}
$$

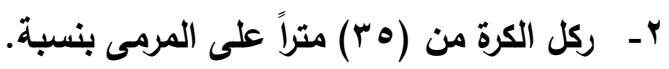

$$
\begin{aligned}
& \text { r- رمية التماس لأبعد مسافة بنسبة. } \\
& \text { الاراسة الاستطلاعية المستخدمة في البحث: }
\end{aligned}
$$

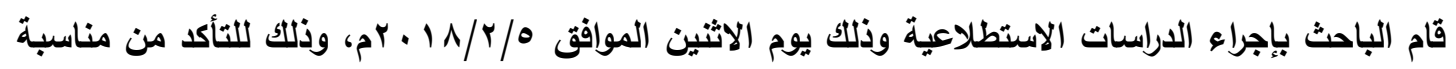

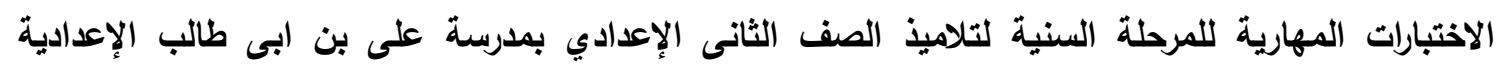

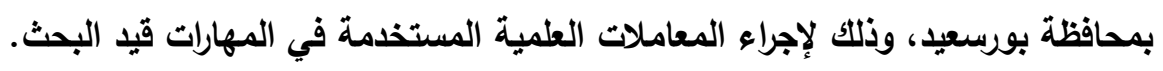

$$
\text { القياس القبلي. }
$$

قام الباحث بإجراء القياسات القبلية على عينة البحث الأساسية (المجموعة الضابطة والمجموعة التجريبية)

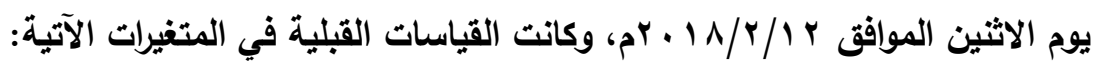


1 - القياسات القبلية الخاصة بمعدلات النمو (السن -الطول-الوزن -درجة الذكاء).

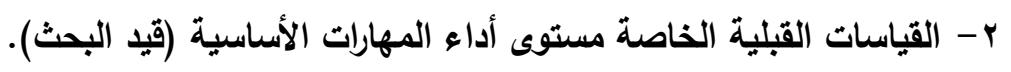

تنفيذ التجرية الأساسية.

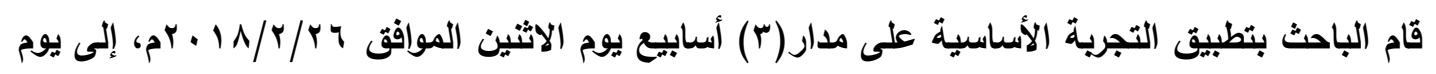

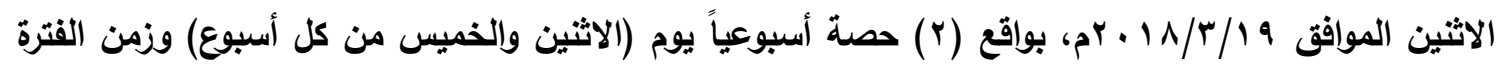
( (9) دقيقة (الشرح والعرض) وذلك من خلال استخدام الهاتف النقال (اللوحي) مع المجموعة التجريبية والأسلوب التقليدي مع المجموعة الضابطة. القياس البعدي. بعد الانتهاء من تنفيذ وتطبيق التجرية الأساسية قام الباحث بإجراء القياسات البعدية على كل من

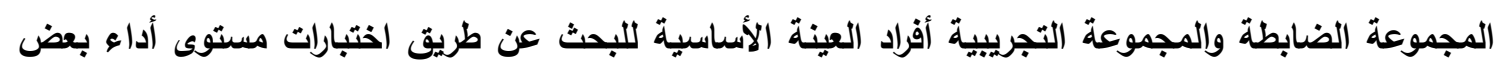

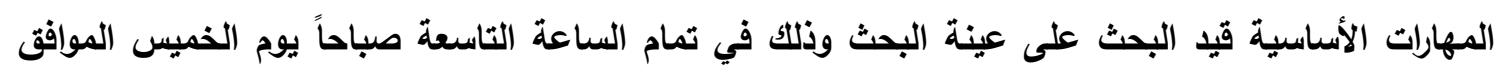

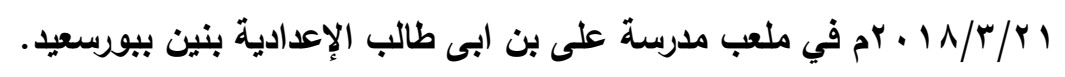

المعالجات الإحصائية.

للتحقق من أهداف البحث واختبارا لصحة الفروض استخدم الباحث حزمة البرنامج الإحصائي للبحوث والعلوم الاجتماعية (SPSS) في المعالجات الإحصائية للبيانات الأساسية.

جدول (0)

دلالة الفروق بين متوسطي القياسين القبلي والبعدي للمجموعة الضابطة في أداء

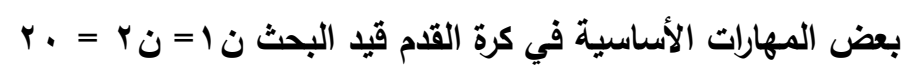

\begin{tabular}{|c|c|c|c|c|c|c|c|c|}
\hline \multirow{2}{*}{ مستوى الدلالة } & \multirow{2}{*}{ قيمة (ت) } & \multirow{2}{*}{ الفرق بين } & \multicolumn{2}{|c|}{ القياس البعدي } & \multicolumn{2}{|c|}{ القياس القبلي } & \multirow[t]{2}{*}{ الإحصاء } & \\
\hline & & & $\varepsilon^{ \pm}$ & س- س - س & $\varepsilon \pm$ & س- س- & & \\
\hline$\cdots$ & r. $9 \varepsilon$ & $\therefore \leqslant 0-$ & 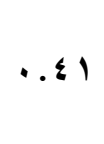 & $1 . r$. &. .00 & $\because v \bullet$ & تصويب الكرة بالرأس نحو & 1 \\
\hline$\cdots r$ & Y. $\varepsilon \varepsilon$ & $\cdots \leqslant 0-$ & $.7 r$ & $\cdot . \wedge$ & $\because \leqslant 9$ &.$r \Delta$ & ركل الكرة من (0ب) متراً & r \\
\hline$\ldots r$ & Y.YA &. $.0 r$ & . & r. 27 & 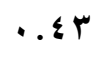 & r.91 & رمية التماس لأبعد مسافة & $r$ \\
\hline
\end{tabular}


يتضح من جدول (•) أن قيمة (ت) الجدولية قـ بلغت بين القياسين القبلي والبعدي للمجموعة الضابطة

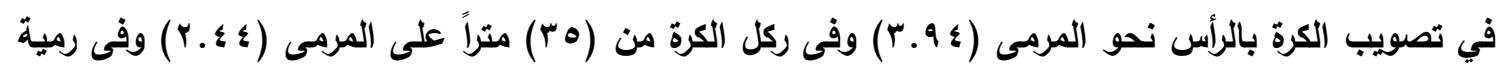

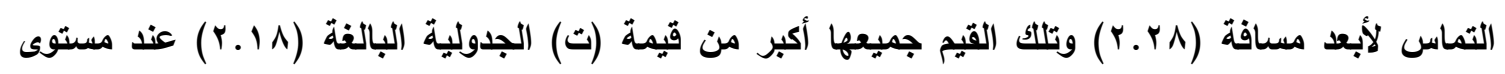

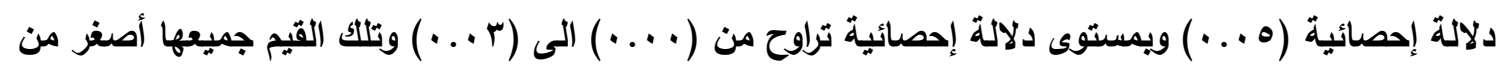

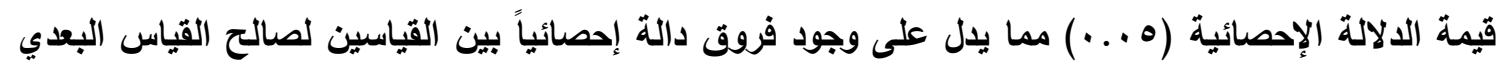
ذا المتوسط الحسابي الأفضل في تلك الاختبارات.

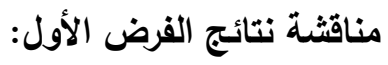

يتضح من نتائج جدول(ه) وجود فروق دالة إحصائية بين متوسطي القياسين القبلي والبعدي

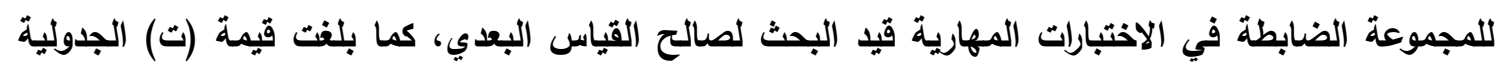

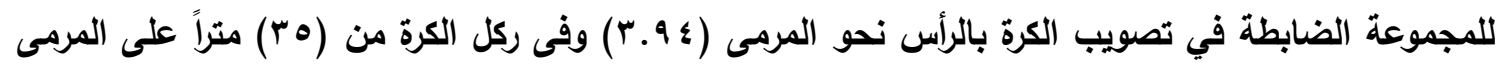

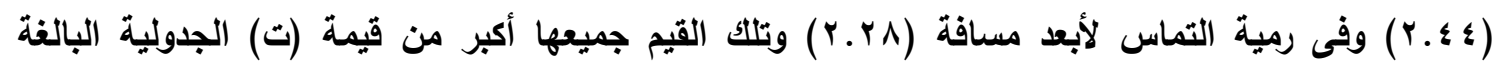

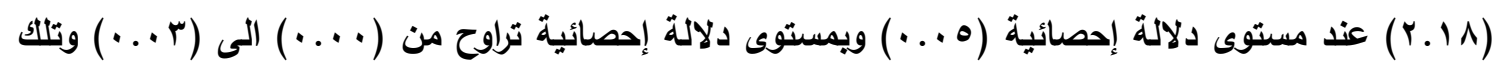

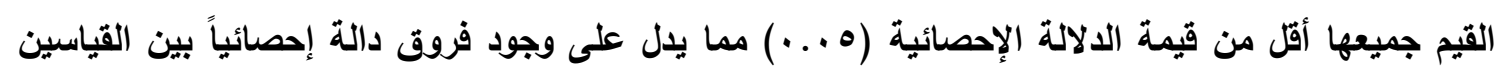

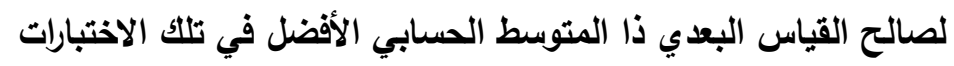

كما يرجع الباحث ظهور تلك النتائج إلى الأسلوب المتبع في تعليم تلاميذ المجموعة الضابطة وما تضمنه من شرح وتعليم لمهارات كرة القدم لتلاميذ الصف الثاني الإعدادي، من حيث الخطوات الفنية وكيفية الأداء بالإضافة إلى النموذج المقدم لكيفية أداء كل مهارة على حده، بالإضافة إلى ما احتواه الأسلوب المتبع في التعليم

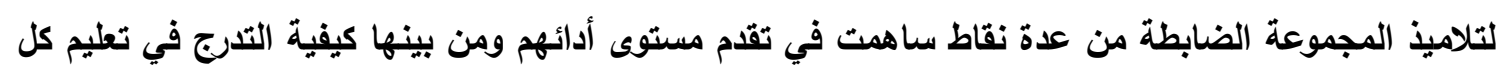
مهارة على حده، مع تصحيح الأخطاء التي تظهر في الأداء والتوجيه أثناء الممارسة التطبيقية في الحصة التصنة ويعزي الباحث أيضا ظهور تلك النتائج إلى أن الطريقة المتبعة (الشرح والعرض) لها تأثير ايجابي في تعليم

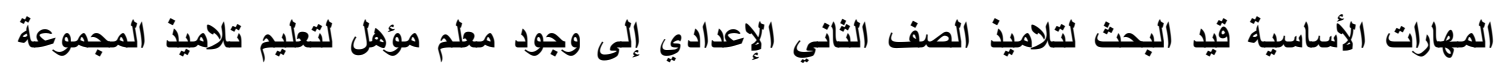

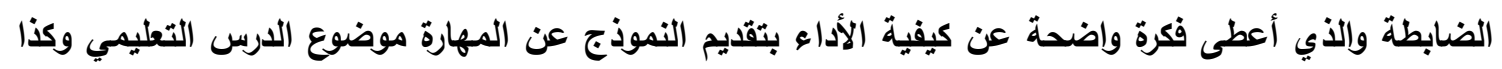

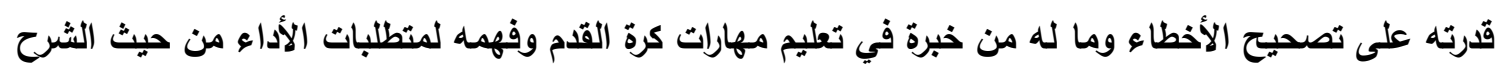
والأداء وتصحيح الأخطاء وكذلك انتظام التلاميذ وجديتهم في أداء الواجب الحركي المكلفين به، فيقوة فئوم المعلم بإصلاح الأخطاء، وإعطاء تغذية راجعة للتلاميذ مما يفيد في تحسين الأداء واكتساب معارف جديدة عن كيفية

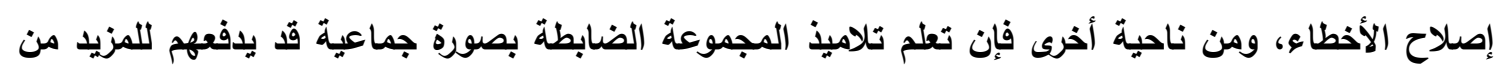

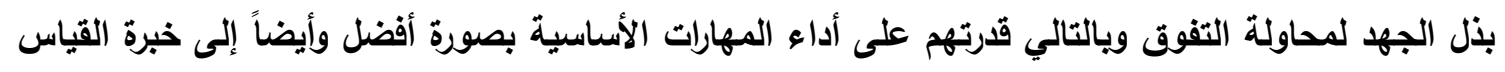
القبلي.

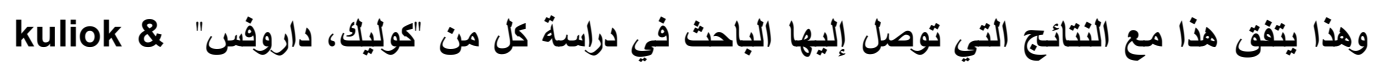

Wraea "r. Driwvs

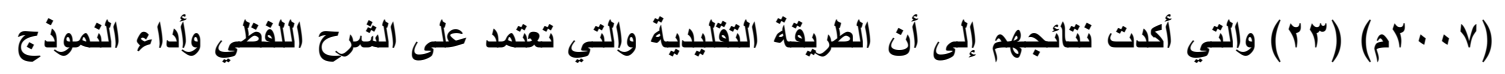
العملي أدت إلى استيعاب التلاميذ للتحصيل المعرفى والمهارات الحركية وتعلمها بشكل إيجابي. 
ويشير "حنفي مختار" ( •99 19) أن قيام المعلم بعمل نموذج مع شرح المهارة وعرض صورة لها فإن

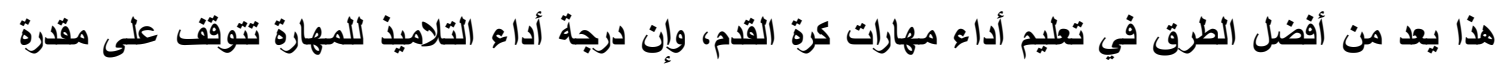
المعلم على الثرح الجيد الدقيق لفن أداء المهارة من حيث صحة الأوضاع لكل أجزاء الجسم خلال عملية

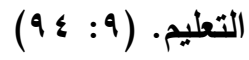

ومما سبق يتحقى صحة الفرض الأول والذي ينص على:

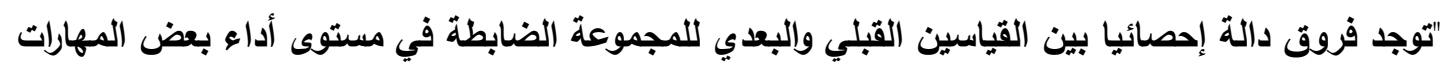
الأساسية فى كرة القدم بدرس التربية الرياضية قيد البحث لصالح القياس البعدي".

عرض ومناقشة نتائج الفرض الثاني. عرض نتائج الفرض الثاني:

(7) (7)

دلالة الفروق بين متوسطي القياسين القبلي والبعدي للمجموعة التجريبية في

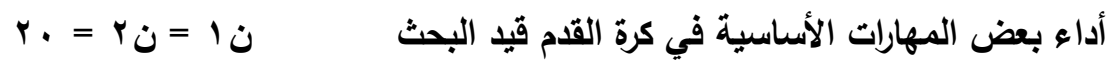

\begin{tabular}{|c|c|c|c|c|c|c|c|c|}
\hline \multirow{2}{*}{ الإلالة الإحصائية } & \multirow{2}{*}{ قيمة (ت) } & \multirow{2}{*}{ الفرق بين } & \multicolumn{2}{|c|}{ القياس البعدي } & \multicolumn{2}{|c|}{ القياس القبلي } & \multirow[b]{2}{*}{ الاختبارات } & \multirow{2}{*}{ p } \\
\hline & & & $\varepsilon \pm$ & 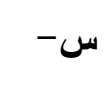 & $\varepsilon \pm$ & 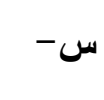 & & \\
\hline$\cdots$ & r.07 & $\cdot .7 \cdot-$ &. .19 & 1.1 &. .19 & $1 . r$. & تصويب الكرة بالرأس نحو المرمى & 1 \\
\hline$\cdots$ & ૧. ५ & $\cdot .9 \cdot-$ & $\cdot . \varepsilon \varepsilon$ & 1.10 &. .09 & or & ركل الكرة من (هب) متراً على & r \\
\hline$\cdots$ & V. 9 . & - &.$\wedge r$ & $\varepsilon .47$ & $\cdot . \wedge \leq$ & s.1T & رمية التماس لأبعد مسافة & $r$ \\
\hline
\end{tabular}

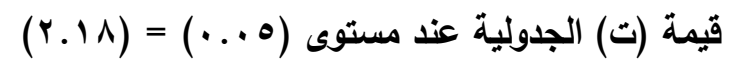

يتضح من جدول (†) أن قيمة (ت) الجدولية قد بلغت بين القياسين القبلي والبعدي للمجموعة التجريبية

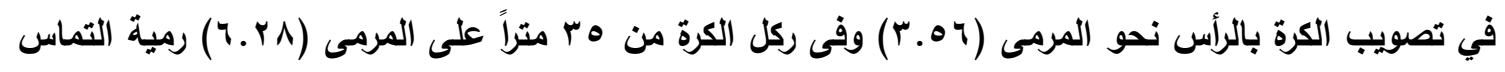

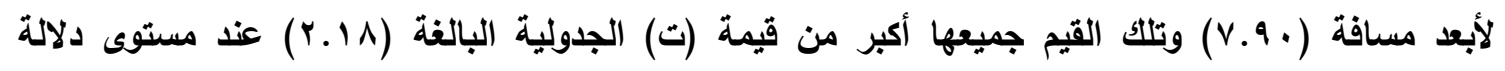

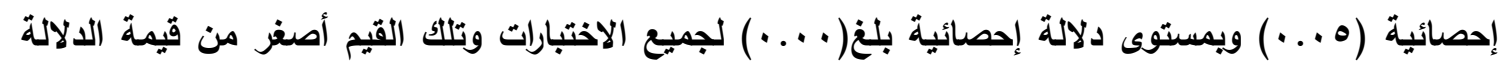

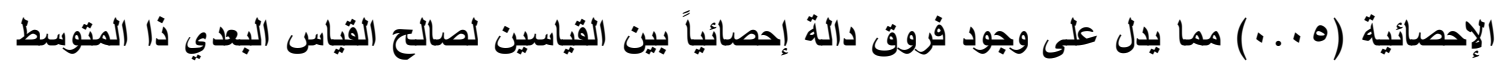
الحسابي الأفضل في تلك الاختبارات. 
يتضح من نتائج جدول(؟) وجود فروق دالة إحصائية بين متوسطي القياسين القبلي والبعدي للمجموعة

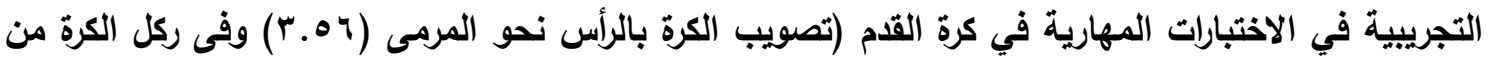

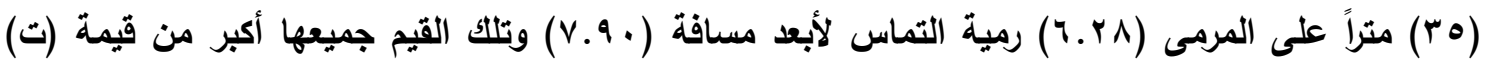

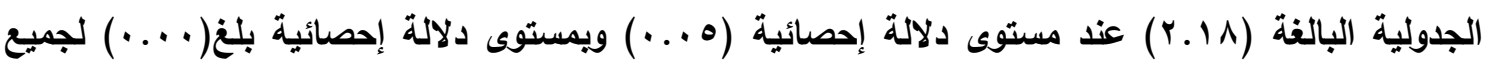

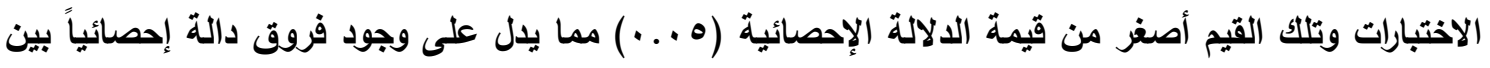
القياسين لصالح القياس البعدي ذا المتوسط الحسابي الأفضل في تلك الاخهـ الاختبارات.

حيث راعى الباحث عند تقديمه للبرنامج التعليمي التنظيم وسهولة تداول تلك المعلومات والمعارف من قبل التلاميذ أثناء العملية التعليمية، كما أن استخدام التلاميذ للهاتف النقال من خلال البرمجية التعليمية الإكترونية المقترحة والمصممة عليه والتي خلقت بيئة تعليمية جيدة من خلال إثرالك جميع حواس التلاميذ واستثارة دوافعه نحو التعلم وجعله يسير في العملية التعليمية، وفقا لرغبته وسرعته وقدراته مما دفع التلاميذ للشعور بذاته وقيمه جئه

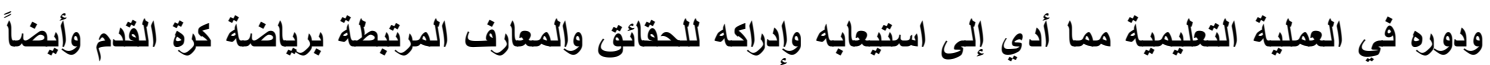

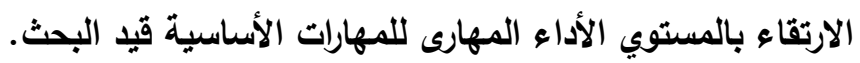

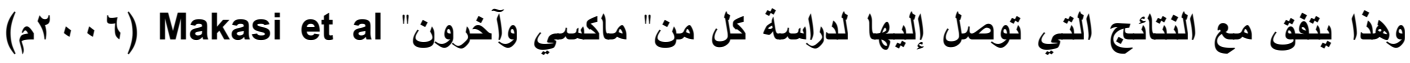

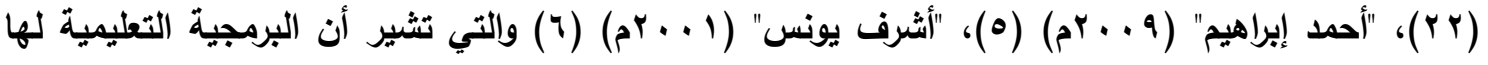
تأثير إيجابي على تحسن مستوي التعلم والأداء للمهارات قيد البحث.

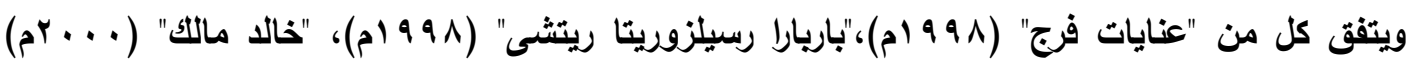

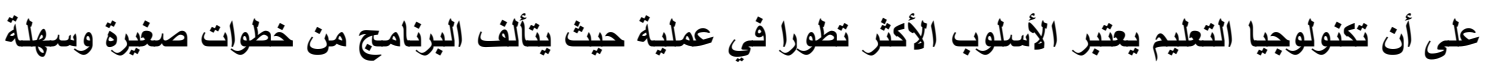

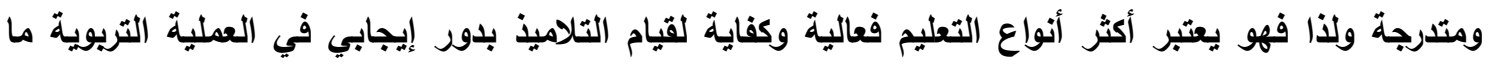

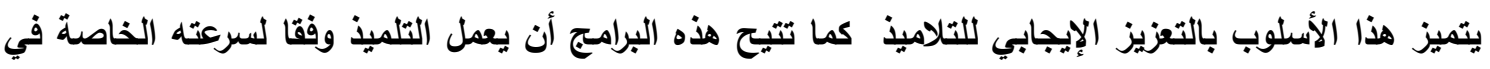

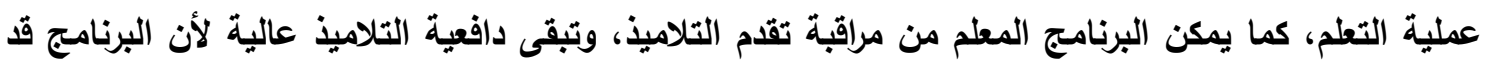

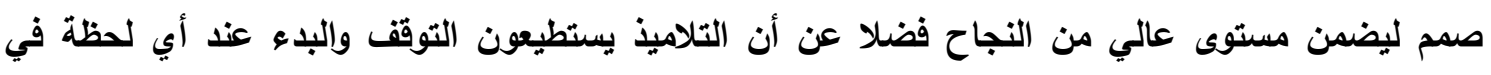

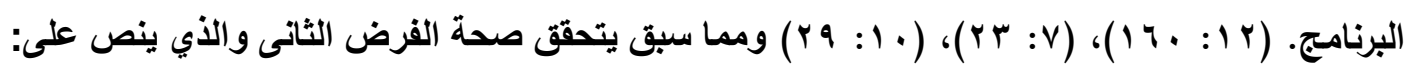
"توجد فروق دالة إحصائيا بين القياسين القبلي والبعدي للمجموعة التجريبية (الهاتف النقال) في مستوى أداء بعض المهارات الأساسية فى كرة القدم بلرس التربية الرياضية قيد البحث لصالح القياس البعدي". 


\section{جدول (V)}

دلالة الفروق بين متوسطي القياسين البعديين للمجموعة التجريبية والمجموعة الضابطة

في مستوى بعض المهارات الأساسية في كرة القدم قيل البحث

\begin{tabular}{|c|c|c|c|c|c|c|c|c|}
\hline مستوى & & & ة التجريبية & المجمو. & ل & 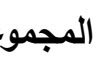 & & \\
\hline & المحسوية & المتوسطين & $\varepsilon \pm$ & س- & $\varepsilon \pm$ & س- & الا & \\
\hline$\ldots 1$ & r.VY & $.7 .-$ &..$\wedge 9$ & $1 . \Lambda$. &.$- \leqslant 1$ & $1 . Y$. & تصويب الكرة بالرأس تحو & 1 \\
\hline$\ldots 1$ & Y. 70 & $\therefore \leqslant 0-$ & • . $\leqslant \varepsilon$ & $1 . r 0$ & $.7 r$ &.$\wedge$ & ركل الكرة من (•ب) متراً على & $r$ \\
\hline$\cdots$ & r.ı. & $1 \ldots-$ &.$\Delta \mu$ & $\varepsilon . \leqslant 7$ &.$\Delta \mu$ & r. & رمية التماس لأبعد مسافة & $r$ \\
\hline
\end{tabular}

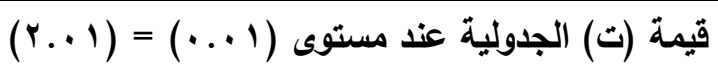

يتضح من جدول (V) أن قيمة (ت) الجدولية قد بلغت بين القياسين البعايين للمجموعتين الضابطة

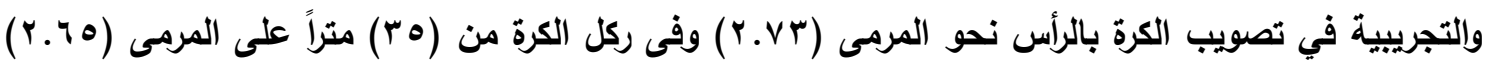

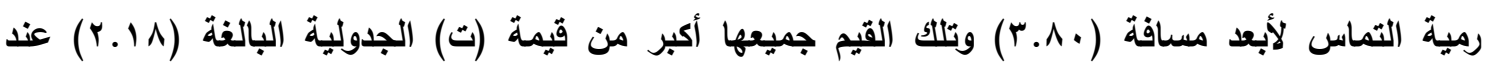

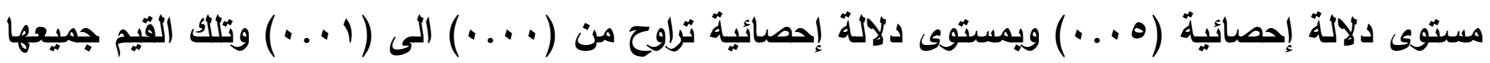
أصغر من قيمة الدلالة الإحصائية (0. . •)، مما يدل على وجود فروق دالة إحصائلة دلائياً بين القياسين البعديين لصالح القياس البعدي للمجموعة التجريبية ذا المتوسط الحسابي الأفضل في تلك الاختبارات. مناقشة نتائج الفرض الثالث:

يتضح من نتائج جدول(V) وجود فروق دالة إحصائية بين متوسطي القياسين البعديين للمجموعتين

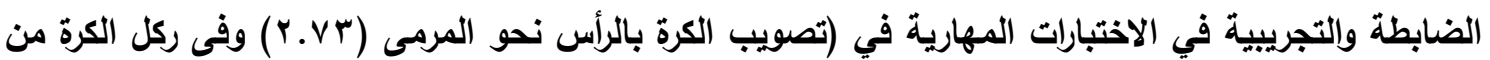

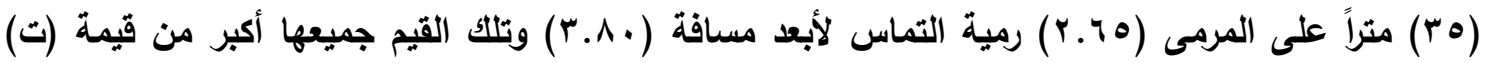

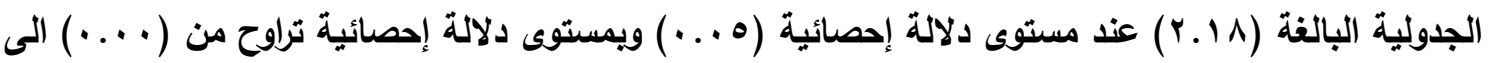

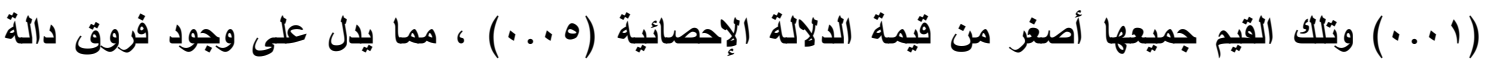
إحصائياً بين القياسين البعديين لصالح القياس البعدي للمجموعة التجريبية ذا المتوسط الحسابي الأفضل في تلك الاختبارات.

ويعزي الباحث هذه الفروق بين متوسطي القياسين البعديين للمجموعتين الضابطة والتجريبية إلى عملية التظيم الجيد للمادة التعليمة من التسلسل المنطقى في عرض المادة التعليمية ومحتواها من الاستخدام الأمثل 
للصور والفيديوهات التعليمية والثرح الوافى لأداء الفني لشكل الجسم عند الأداء وكذلك توافر التدريبات المختلفة والمتدرجة عند عرض المادة التعليمية ومحتواها بطريقة سهلة، كما أن استخدام الهاتف النقال ساعد على التعلم من خلال مسايرة التطورات التكنولوجية ومسايرة العصر وشعور التلاميذ بالسعادة وتحقيق الذات من خلال الاستخدام الأمثل للأجهزة الاكترونية بطريقة إيجابية في التعليم.

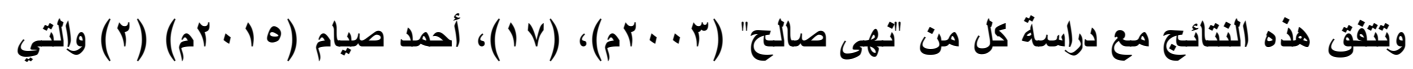
أكلت على تفوق المجموعة التجريبية المستخدمة للأساليب التكنولوجية الحديثة على المجموعة الضابطة المانة المستخدمة الطريقة التقليدية في التعليم.

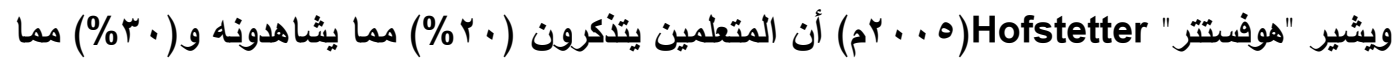

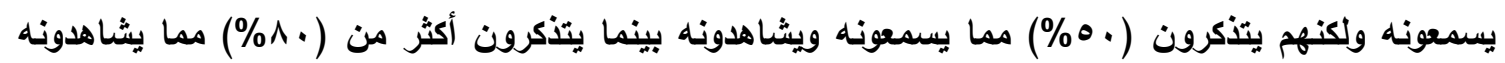

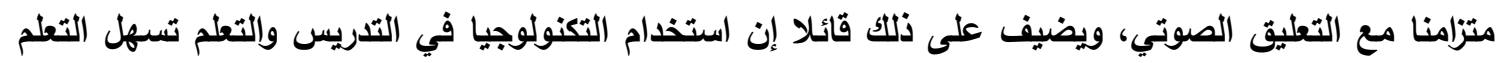
لمختلف عناصر المحتوي الاراسي والعلاقات بينهما ومتطلبات تعلمها، وتجعل ما يتعلمه المتعلم ذا معني وذلكاتك

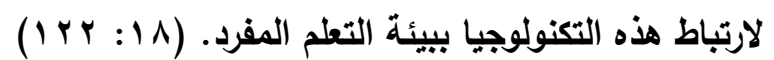
ومما سبق يتحقق صحة الفرض الثالث والأي ينص على: "توجد فروق دالة إحصائيا بين القياسات البعدية للمجموعة الضابطة والمجموعة التجريبية (الهاتف النقال) في مستوى أداء بعض المهارات الأساسية فى كرة القدم بدرس التربية الرياضية قيد البحث لصالح المجموعة التجريبية".

الاستتتاجات:

1- أن الهاتف النقال ساهمت بطريقة إيجابية في تعلم بعض المهارات الأساسية لكرة القدم قيد البحث

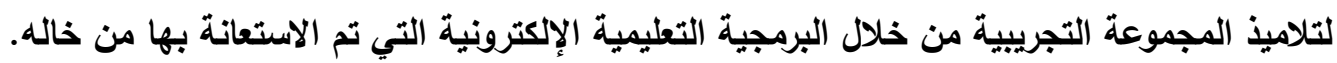

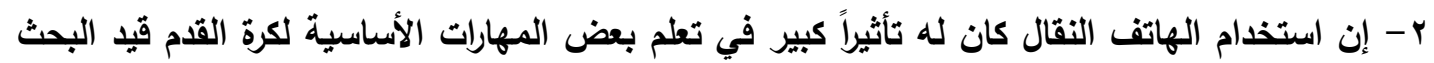
من طريقة (العرض والثرح) المعتادة مما يدل على فاعليته وتأثيره في تعلم بعض مهاتئ كهارات كرة القدم.

\section{التوصيات.}

في ضوء الاستتتاجات التي توصل اليها الباحث فإن الباحث يوصي بالأتي:

ا. يجب أن تتوافر أجهزة الهاتف النقال في المدارس واستخدامها في عملية تعلم المهارات الحركية بالأنشطة الرياضية بصفة عامة ورياضة كرة القدم بصفة خاصة بدرس التربية الرياضية.

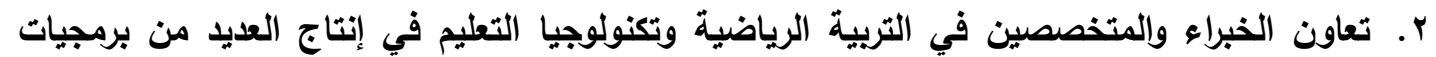

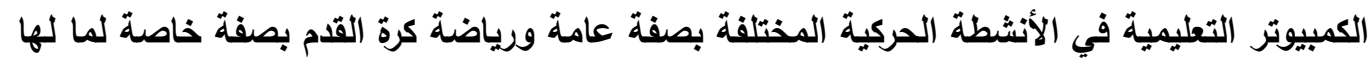
من مردود إيجابي على كل من المعلم والتلميذ. 
1 - أحمد زكي صالح: (9^19 ام)، "علم النفس التريوي"، ط(ب ا)، مكتبة النهضة المصرية، القاهرة. Y - أحمد على صيام:(10 • 1 م)، "فاعلية الكتيب الإكتروني على تعلم بعض المهارات الأساسية لكرة القدم لتلاميذ المرحلة الإعدادية"، رسالة دكتوراه، كلية التربية الرياضية بنين، جامعة الزقازيق،

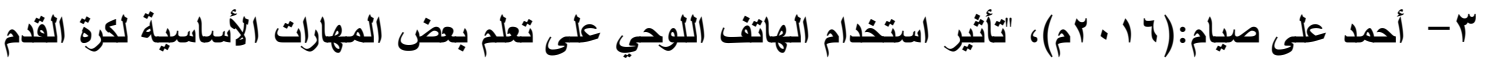

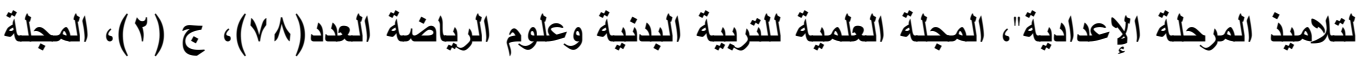
العلمية لكلية التربية الرياضية للبنين جامعة حلوان.

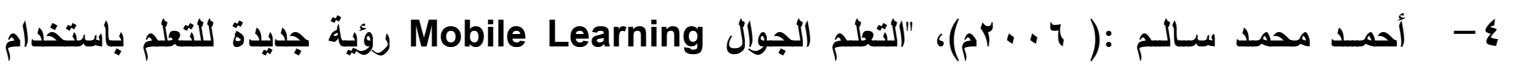
التقتيات اللاسلكية"، ورقة عمل مقدمة إلى المؤتمر العلمي الثامن عشر للجمعية المصرية للمناهج

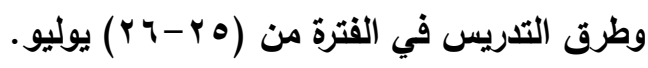

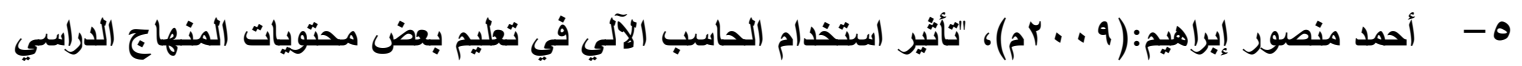
لكرة القدم للمرحلة الثانوية"، رسالة دكتوراه، كلية التربية الرياضية للبنين، جامعة الزقازيق. צ- - أشرف صبحي يونس:(1 . . Yم)، "فاعلية برنامج قائم على التعليم المدمج لتنمية مهارات التدريس

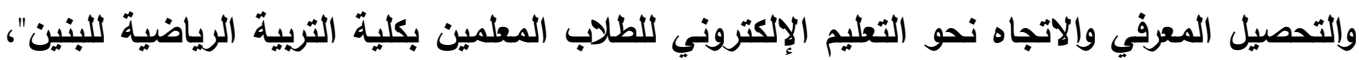
رسالة دكتوراه، كلية التربية الرياضية للبنين بأبو قير، جامعه الإسكندرية. - V - باريارا رسيلز، ريتاريتشى:(9191م)، "تكنولوجيا التعليم-التعريف ومكونات المجال"، ترجمة بدر بن عبد

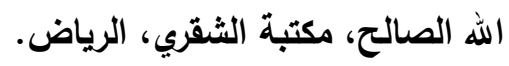

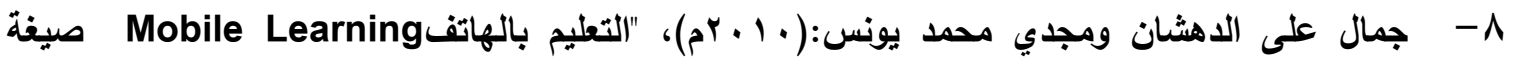
جليدة للتعليم عن بعد"، المؤتمر الدولي الأول للجمعية العمانية لتكنولوجيا التعليم، سلطنة عمان، من بانه

$$
\text { • (^) }
$$

9- حنفي محمود مختار:( •99 (19)، " الأسس العلمية في تدريب كرة القدم "، دار الفكر العربي للنشر والتوزيع، القاهرة.

• 1 - خالدمصطفمالك:( . . . rم)،" تكنولوجيالتعليمالمفتوح"، عالمالكتب للنشر والتوزيع،القاهرة.

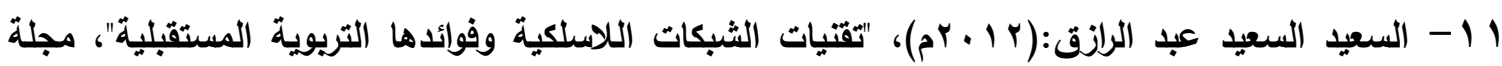

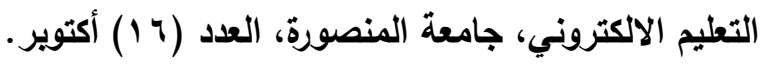

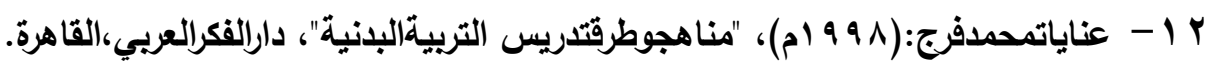

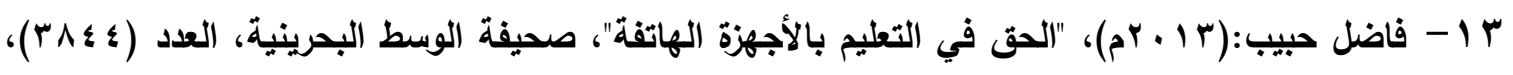
(IV) ع ا- مجدي صلاح المهدي:(1 . . r م)، التعلم الافتراضي، فلسفته، مقوماته، فرص تطبيقه، دار الجامعة

$$
\text { الجديدة، الإسكندرية. }
$$

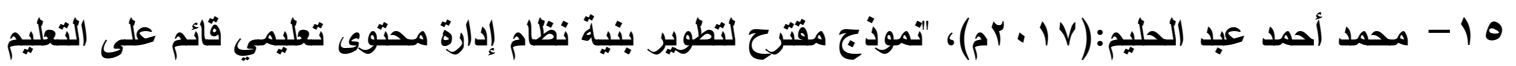

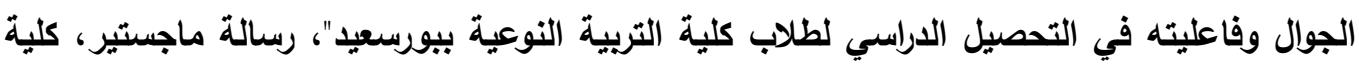


I 1 - ميرفت سمير حسين:(T . . rم)، "فعالية برنامج تعليمي مقترح باستراتيجية كيلر (تفريد التعليم) باستخدام

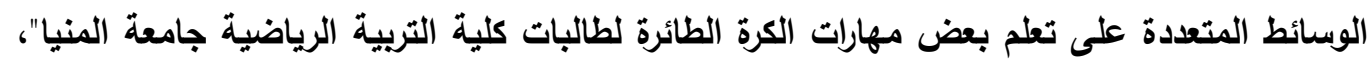

رسالة دكتوراه، كلية التربية الرياضية، جامعة المنيا.

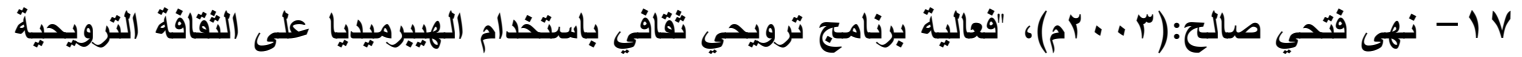
الخلوة"، رسالة ماجستير، كلية التربية الرياضية، جامعة المنيا.

18- Hof Stetter F :( 2005), "Multimedia Literacy", New York, Mc Grqw Hill,.

19- Kim, Hea-Suk, :(2014), Effects of using mobile devices in blended learning for English reading comprehension Multimedia-Assisted Language Learning, Seoul Women's University 17(2), 64-85, .

20- Kuliok, C., Driwvs Baergert:(2003), "Effect ivieness of Mastery learning Programs Ameta -Analysis "Review of Educational research Vol. 60, No 2.

21- Mac Callum, K., Jeffrey, L., \& Kinshuk,. :( 2014), Factors impacting teachers'Adoption of mobile learning. Journal of Information Technology Education: Research, 13.

22- Makasi et, al :( 2006), " effects of interactive, computer based, cd room Instruction on improving psy clement orkill analy sis ability of soccer skills " second edition Columbus, iarlese college, P.e teaching journal of sports science in china.

23- Wraea, A :( 2007), "Self-paced learning with video for under Graduates Multimedia Keller plan", British Journal of educational Technology, vol 24 No 1. 


\section{مستخلص البحث}

فاعلية برنامج تعليمي مدعم بالهاتف النقال على مستوى أداء بعض المهارات الأساسية في كرة القدم بدرس التربية الرياضية

"حسام محمد أحمد القليويب "

يهذف هذا البحث إلى محاولة التعرف على فاعلية برنامج تعليمى مدعم بالهاتف النقال على مستوى أداء بعض

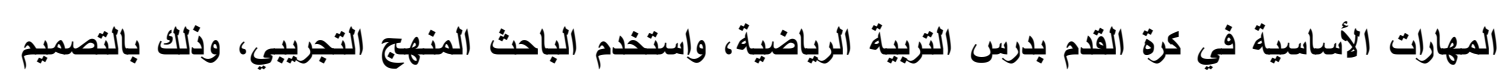
التجريبي لمجموعتين إحداهما ضابطة، والأخرى تجريبية، يتمثل مجتمع البحث الحالي من تلاميذ المرحلة

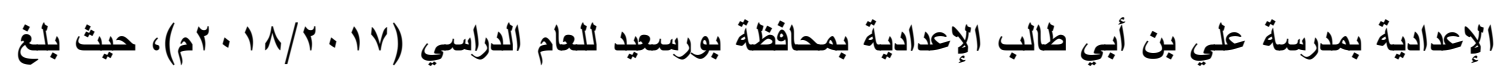
عينة البحث (0 (1) تلميذاً،وكاتت أهم النتائج أن الهاتف النقال ساهم بطريقة إيجابية في تعلم بعض المهارات الأساسية لكرة القدم قيد البحث لتلاميذ المجموعة التجريبية من خلال البرمجية التعليمية الإلكترونية التي تم الاستعانة بها.

الكلمات المفتاحية : الهاتف النقال 


\section{Abstract \\ Effectiveness of an educational program supported by mobile phone on the level of performance of some basic skills of football in physical lesson}

*Hossam Mohamed Ahmed El Kalyoubi

This research aims To try to identify the effectiveness of a educational program supported by mobile phone on the level of performance of some basic skills in football in physical education lesson, theresearcher used the experimental method, of experimental design of two groups, one experimental and control experimental. The current research community consists of the students of the preparatory stage of Ali bin Abi Talib Preparatory School in Port Said Governorate for the academic year 2017/2018. The research sample include of pupils (215)The most important results showed that the mobile phone contributed in a positive way to learning some of the basic skills of football in search of the pupils of the experimental group using the e-learning program that was used.

Key Words : Mobile phone 